\title{
DEVELOPING AN EMERGENCY RESPONSE MODEL FOR OFFSHORE OIL SPILL DISASTER MANAGEMENT USING SPATIAL DECISION SUPPORT SYSTEM (SDSS)
}

\author{
A. L. Balogun ${ }^{1, *}$, A.N. Matori ${ }^{1}$, K. W. Toh Kiak ${ }^{1}$ \\ ${ }^{1}$ Geospatial Analysis and Modelling Research Group (GAMR), Dept. of Civil and Environmental Engineering, 32610 Seri Iskandar, \\ Malaysia - alateef.babatunde@utp.edu.my
}

KEY WORDS: Disaster Management, Emergency Response, ESR, Oil Spill, SDSS,

\begin{abstract}
:
Environmental resources face severe risks during offshore oil spill disasters and Geographic Information System (GIS) Environmental Sensitivity Index (ESI) maps are increasingly being used as response tools to minimize the huge impacts of these spills. However, ESI maps are generally unable to independently harmonize the diverse preferences of the multiple stakeholders' involved in the response process, causing rancour and delay in response time. This paper's Spatial Decision Support System (SDSS) utilizes the Analytic Hierarchy Process (AHP) model to perform tradeoffs in determining the most significant resources to be secured considering the limited resources and time available to perform the response operation. The AHP approach is used to aggregate the diverse preferences of the stakeholders and reach a consensus. These preferences, represented as priority weights, are incorporated in a GIS platform to generate Environmental sensitivity risk (ESR) maps. The ESR maps provide a common operational platform and consistent situational awareness for the multiple parties involved in the emergency response operation thereby minimizing discord among the response teams and saving the most valuable resources.
\end{abstract}

\section{INTRODUCTION}

Presently and since inception, oil and gas exploration and transportation have predominantly been onshore (Balogun, 2014; Smith, 2012). However, recent discoveries about the benefits of offshore exploration are beginning to stir more interest in offshore product transportation. Offshore or subsea configuration has merits over an onshore alternative. Offshore solutions offer a significant reduction in community disturbances and are an environmentally sound alternative to onshore structures (Nord Stream, 2012; 2008; Hegde, 2001). Subsea pipelines transport more gas at sustained pressures than onshore systems thereby lowering negative human and environmental impacts. Moreover, onshore routes utilize compressor stations which are potential sources of emission (Zenobi et al., 2012). Furthermore, the continuous depletion of onshore oil and gas reserves is compelling companies to seek alternatives in offshore solutions.

Despite its many benefits, offshore exploration has lots of challenges too. Offshore disasters and subsequent pollution could occur due to multiple factors such as offshore oil rig mishaps, oil spillage from ships, and accidents on oil crude tanks etc. These incidents do not only affect humans but also the marine creatures and the marine environment (NOAA, 2017; Chiau, 2005; Singkran, 2003). Pollution emanating from exploration and exploitation activities usually have adverse effects on the surrounding region. The adjoining environment is heavily polluted, threatening the very existence of plants, animals, and humans (Ansa \& Akinrotimi, 2018). Poisonous chemical components from spilled oil can harm living things, causing skin and eye irritation. Oil can also smother some species of fish or invertebrates and coat feathers and fur, reducing birds' and mammals' ability to maintain their body temperatures. Plants and animals in the marine environment are generally susceptible to the impacts of oil spill.

During Exxon Valdez crude oil spill disaster on Bligh reef in 1989, several parts of the Alaskan marine environment were severely affected: waters experienced rise in temperature, ice receded, and populations of fish and mammals declined significantly. 28 different species of animals, plants, and marine habitats were directly affected in Alaska's Prince William Sound. 250,000 birds died, representing up to 40 percent of the seabirds' population. It took over 10 years for Salmons and common murres to recover after the incident while the subtidal communities, rockfish, sea otter and ducks were only able to recover two decades after the disaster. Species like the killer whale pigeon Guillemots are not showing signs of recovery yet (NOAA, 2017). The Deepwater Horizon Oil Spill disaster killed 11 workers and will cost British Petroleum (BP) over \$18.7 billion for restoration to address natural resources injuries, lost recreational uses, and other settlements. This is the largest environmental disaster in America's history and the most expensive (Lynch, 2015). Such monumental damages often create hostile relationships and sometimes conflicts between the oil companies and coastal communities at the receiving end of exploration disasters.

A major cause of the aggravation of the impacts of such disasters is the absence of valuable and timely spatial information on the location and relative risk level of various assets at the time of the incidents. An emergency response

\footnotetext{
* Corresponding author
} 
Spatial Decision Support System (SDSS), comprising data on local environment and associated risks at the scene of the spill is essential. Environmental sensitivity risk (ESR) maps will enable decision makers, responders and volunteers to make informed and prompt decisions about how to deal with the disaster. Several habitats, birds, mammals etc. can be adversely impacted by oil spills and deploying limited resources to save all the habitats and natural resources could be daunting. It is therefore necessary to prioritise the various resources at risk in order of significance, and adopt a systematic approach to the disaster response. This poses a huge challenge because the diverse interests of the people involved in the disaster makes it difficult to swiftly reach a consensus and work harmoniously. Different individuals/groups usually have different priorities so a reliable priority indexing of resources that are likely to be affected by oil spills is crucial. An oil spill response system typically requires the interaction and cooperation of these multiple stakeholders and organizations with diverse interests, who combine resources and efforts to perform tasks beyond their individual capabilities. Thus decision makers and emergency response teams must often consider tradeoffs between the many vital offshore resources during a response.

A few models have been developed for oil spill response planning and visualization (Fingas, 2012; Brimicombe, 2010). However, facilitating a reliable tradeoff and bringing about consensus among the respective stakeholders on the priority level of the several offshore resources remains a challenge. Data-rich SDSS can reliably facilitate this tradeoffs and produce one common operational picture via ESR maps, thereby providing consistent situational awareness for the multiple parties involved. This paper develops an emergency response model capable of aggregating the preferences of the various stakeholders and presenting generally acceptable ESR maps of the offshore disaster region, which will facilitate a timely and effective response to the disaster while minimizing disagreements among the respective stakeholders.

\section{MATERIAL AND METHODS}

The study area stretches $20.8 \mathrm{~km}$ offshore Sarawak, south china sea, Malaysia (see Figure 1). A minimum water depth of $55.5 \mathrm{~m}$ below MSL and maximum water depth of $70.9 \mathrm{~m}$ below MSL is observed at the area. Existing structures within this area include mooring buoys, vents, platforms, pipelines and mattress. Shipping activities are also present. Sarawak has a vibrant marine ecosystem (Chemsain, 2014), with several valuable resources at risk in the event of an oil spill. Nine primary environmental resources have been identified in Table 1 .

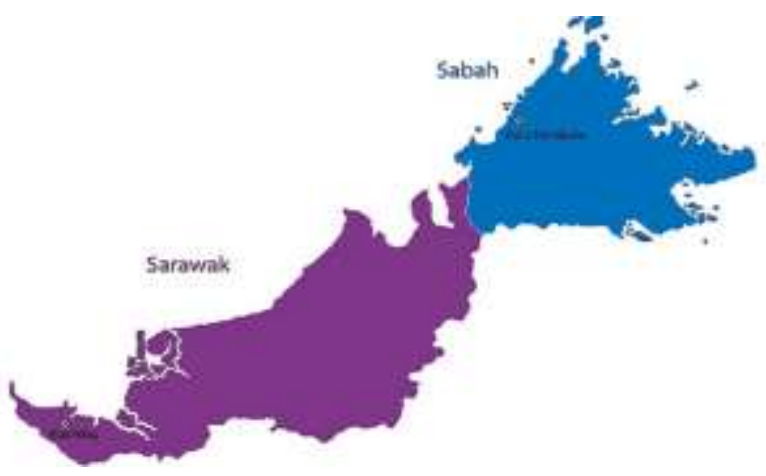

Figure 1: Study Area

\begin{tabular}{|l|l|}
\hline Symbol & $\begin{array}{c}\text { Environmental } \\
\text { Resources at risk }\end{array}$ \\
\hline A1 & Aquaculture Fish \\
\hline A2 & Turtle nesting \\
\hline A3 & Coral reefs \\
\hline A4 & Crab fishing \\
\hline A5 & Crocodiles \\
\hline A6 & Dolphins \\
\hline A7 & Mangrove \\
\hline A8 & Prawns \\
\hline A9 & Shorebirds \\
\hline
\end{tabular}

Table 1: Environmental resources at risk in the study area

A Spatial Decision Support Systems (SDSS) was developed by integrating a GIS platform with experts' feedback on the sensitivity and relative priority level of each environmental resource in comparison to another. An Analytic Hierarchy Process (AHP) model was used for qualitative ranking of risk assessment and sensitivity analysis for the resources of the oilrich study area. These rankings were incorporated in GIS to produce ESR maps showing the locations and risk level of the various resources.

\subsection{Rasterization of vector layers}

Spatial data representing each of the nine resources in Table 1 were converted from their default vector format to raster. This is necessary because raster structures generally handle such analysis better (Eastman et al., 1995). Figure 2 shows the rasterization procedure in the GIS platform.

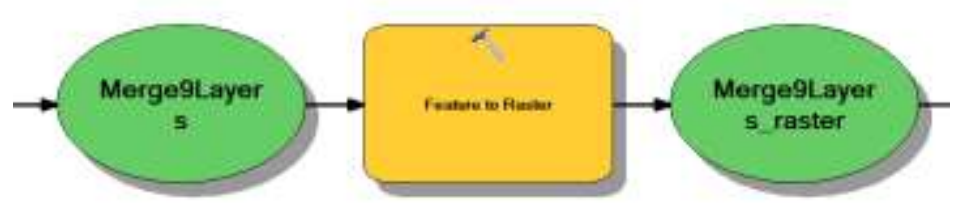

Figure 2: Conversion of vector layers to raster

\subsection{Reclassification}

We subsequently reclassified the rasterized output in order to establish a consistent scale for each layer representing each of 
the nine marine resources. Figure 3 shows the reclassification process in the GIS platform

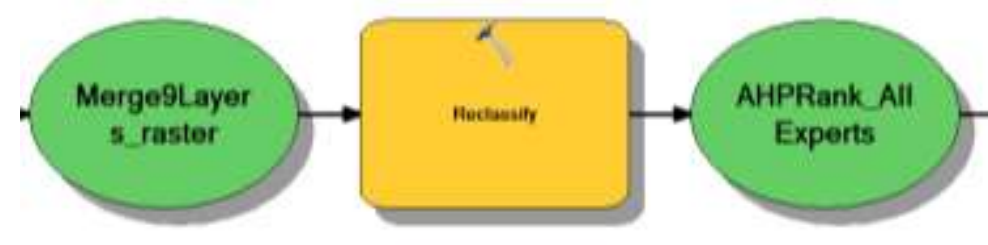

Figure 3: Reclassification of rasterized layers

Rather than utilize the default reclassification values in assigning weights to the offshore resources, AHP was used to derive a scale of relative importance. This is because the diverse preferences of multiple stakeholders and decision makers who make up the emergency response team, are not accurately represented by standalone GIS platforms (Chakhar and Martel, 2003; Balogun, 2014). The AHP relative significance procedure is discussed in the next section.

\subsection{Scaling of marine resources using AHP model}

Four expert respondents were requested to complete an AHP survey questionnaire designed to rank the 9 marine resources in order of importance. The respondents are chosen based on their expertise and experience in the offshore oil exploration domain. The consideration of several respondents is meant to avoid some bias in the computation of respondent judgments, otherwise a single expert's judgment is sufficient (Balogun et al., 2016). If a single judge is experienced and well versed in an area, his individual expertise can be relied on to provide the judgments (Saaty and Özdemir 2015). Balogun et al. (2015) and Saaty (1990) detailed the steps in AHP implementation, which are utilized in this study. Each of the four expert respondents in this study has over ten years' experience in offshore field operations and are thus competent to provide valid ratings of the marine resources.

The decision matrices are composed of elements $\mathrm{a}_{\mathrm{ij}}$, which represents the order of preference between indicator/objective $i$ and indicator/objective $\mathrm{j}$. The values of $\mathrm{a}_{\mathrm{ij}}$ are assessed using pairwise comparison. Table 2 shows the pair-wise comparison scale of judgement of the relative significance of each resource in the event of an oil spill. Resources that are considered more important are ranked higher i.e. 6 or higher while resources that are considered less significant are ranked lower i.e. 4 or less.

Feedback from the experts' AHP analysis was further classified into a sensitivity index scale comprising five distinct classes: Very high significance, high significance, medium significance, low significance and very low significance. Details of the sensitivity index are presented in the next section.

\begin{tabular}{|c|c|c|}
\hline Numerical rating & Definition & Details \\
\hline 1 & Equal importance & $\begin{array}{l}\text { Two elements are } \\
\text { of equal } \\
\text { importance in the } \\
\text { decision making } \\
\text { process }\end{array}$ \\
\hline 3 & $\begin{array}{l}\text { Moderate } \\
\text { importance of one } \\
\text { over another }\end{array}$ & $\begin{array}{l}\text { Experience and } \\
\text { judgment slightly } \\
\text { favour one element } \\
\text { over another. }\end{array}$ \\
\hline 5 & Strong importance & $\begin{array}{l}\text { Experience and } \\
\text { judgment } \\
\text { moderately } \\
\text { strongly favour } \\
\text { one element over } \\
\text { another. }\end{array}$ \\
\hline 7 & $\begin{array}{ll}\text { Very } & \text { strong } \\
\text { importance } & \end{array}$ & $\begin{array}{l}\text { An element is } \\
\text { strongly favourable } \\
\text { and its dominance } \\
\text { is demonstrated in } \\
\text { practice. }\end{array}$ \\
\hline 9 & $\begin{array}{l}\text { Extreme } \\
\text { importance }\end{array}$ & $\begin{array}{l}\text { The evidence of } \\
\text { favouring one } \\
\text { element over } \\
\text { another is of the } \\
\text { highest possible } \\
\text { order of } \\
\text { affirmation. }\end{array}$ \\
\hline $2,4,6,8$ & $\begin{array}{l}\text { Intermediate } \\
\text { values between the } \\
\text { two adjacent } \\
\text { judgments }\end{array}$ & $\begin{array}{l}\text { When compromise } \\
\text { is needed. }\end{array}$ \\
\hline 3 & $\begin{array}{l}\text { Moderate } \\
\text { importance of one } \\
\text { over another }\end{array}$ & $\begin{array}{l}\text { Experience and } \\
\text { judgment slightly } \\
\text { favour one element } \\
\text { over another. }\end{array}$ \\
\hline
\end{tabular}

Table 2: Pairwise Comparison Scale of Judgment preferences in AHP (Moussaoui et al., 2017; Saaty, 1990) 


\section{RESULTS}

\begin{tabular}{|c|c|c|c|c|c|c|c|c|c|}
\hline Responde & nt 1 & & & & Respond & dent 2 & & & \\
\hline & Rank (\%) & Rank & & & & Rank (\%) & Rank & & \\
\hline Turtie & $\begin{array}{r}28.27 \\
\end{array}$ & 1 & & & Fish & 26.90 & 1 & & \\
\hline Coral & 25,41 & 2 & & & Shorebi & 18.25 & 2 & & \\
\hline Fish & 10.71 & 3 & & & Prawns & 18.20 & 3 & & \\
\hline Crab & 10.35 & 4 & & & Crab & 17.12 & 4 & & \\
\hline Dophlins & 9.03 & 5 & & & Mangro & 9,11 & 5 & & \\
\hline Crocodile & 8.02 & 6 & & & Crocodi & 2.98 & 6 & & \\
\hline Shorebird & 3.26 & 7 & $\mathrm{Cl}=$ & 0.14 & Turtle & 2.97 & 7 & $\mathrm{Cl}=$ & 0.08 \\
\hline Mangrove & 3.14 & 8 & $R i=$ & 1.46 & Coral & 2.44 & 8 & $R i=$ & 1,46 \\
\hline Prawns & 1.81 & 9 & C. Ratio $=$ & 0.09 & Dophlin & 2.04 & 9 & C. Ratio $=$ & 0.06 \\
\hline
\end{tabular}

Table 3: Prioritization of marine resources at risk by experts 1 and 2

\begin{tabular}{|c|c|c|c|c|}
\hline \multicolumn{3}{|c|}{ Respondent 3} & & \\
\hline & Rank (\%) & Rank & & \\
\hline Prawns & 30.35 & 1 & & \\
\hline Crab & 19.42 & 2 & & \\
\hline Fish & 16.09 & 3 & & \\
\hline Coral & 11.26 & 4 & & \\
\hline Turtle & 8.25 & 5 & & \\
\hline Dophlins & 5.34 & 6 & & \\
\hline Mangrove & 4.11 & 7 & $\mathrm{Cl}=$ & 0.12 \\
\hline Shorebird & 3.39 & 8 & Rin & 1.46 \\
\hline Crocodile & 1.78 & 9 & C. Ratio= & 0.08 \\
\hline
\end{tabular}

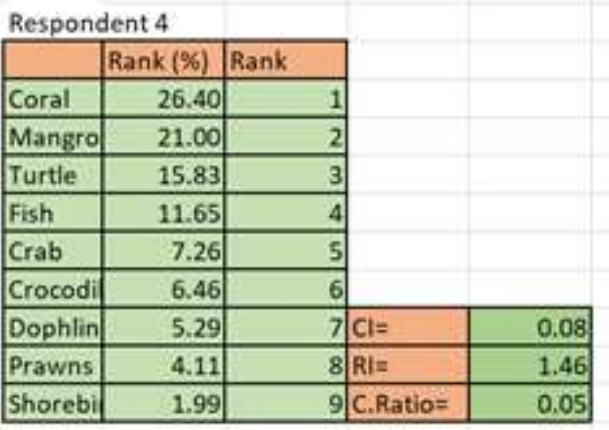

Table 4: Prioritization of marine resources at risk by experts 3 and 4

Each of these ranks are used to generate relative importance indices of the marine resources, which are represented in the ESR maps in Figures 4-7.

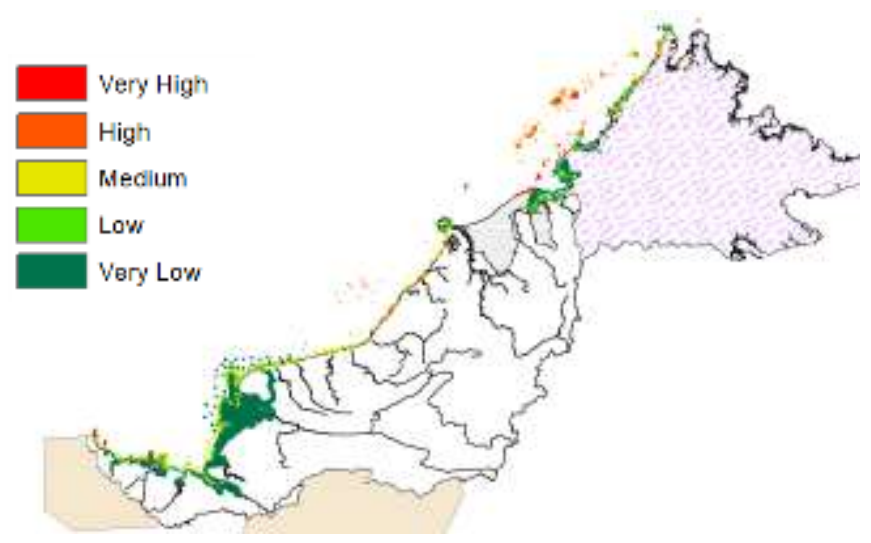

Figure 4: ESR map based on expert 1's scaling

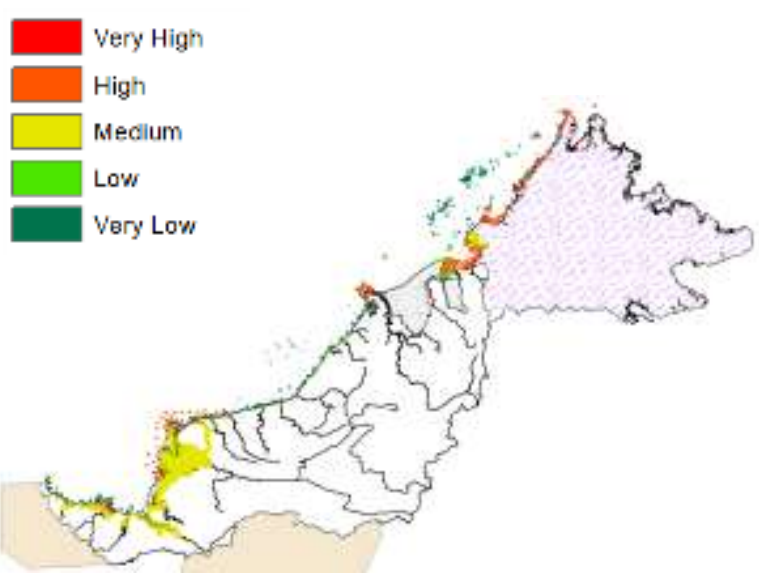

Figure 5: ESR map based on expert 2's scaling 


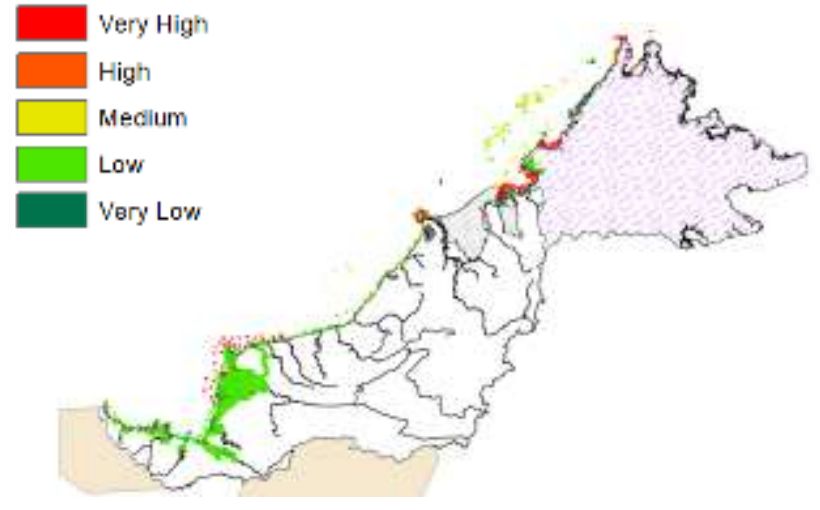

Figure 6: ESR map based on expert 3's scaling

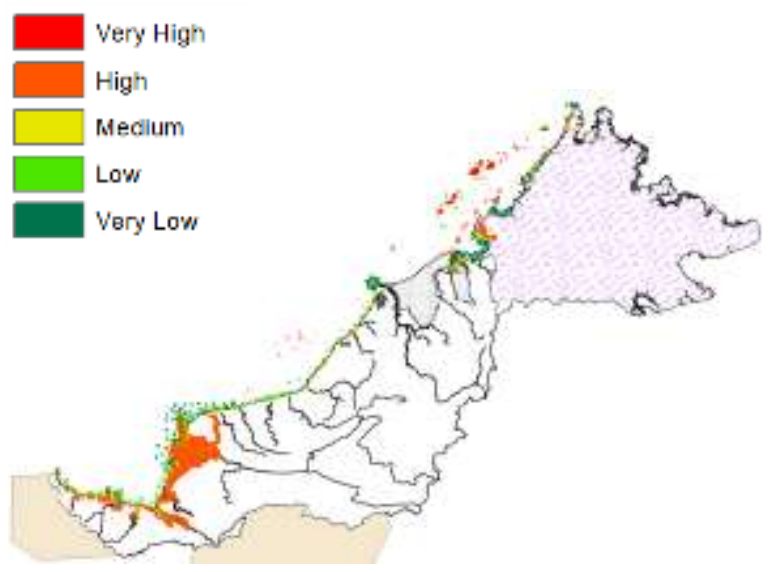

Figure 7: ESR map based on expert 4's scaling

\section{DISCUSSION AND CONCLUSION}

From Tables 3 and 4, the consistency ratios (CR) of the four respondents are as follows: 0.09, 0.06, 0.08, and 0.05 respectively. This relative priority scaling of resources is acceptable since the values of $\mathrm{CR}<0.10$ in all rankings. Otherwise, the procedure ought to be reviewed (Moussaoui et al., 2017; Saaty, 1990; Al-S. Al-Harbi, 2001). A significant disparity is observed in the ratings of experts 1 and 2 . While the first expert highly prioritized turtles by assigning it the highest weight of $28.27 \%$, the second respondent considered turtles of little significance in the event of an oil spill disaster. This is reflected in its low weightage of $2.97 \%$. However, both respondents assigned very high weights to Fish, which was rated $3^{\text {rd }}$ and $1^{\text {st }}$ on the respective scaling indexes. The high significance of fish is also observed in the ratings of experts 3 and 4 , who ranked it $3^{\text {rd }}$ and $4^{\text {th }}$ respectively. This reflects a consensus among the different experts on the relevance of protecting fish in the event of an oil spill disaster offshore. The coral is another resource which is generally considered very important by most of the respondents and given high rescue priority during disasters. Crocodile is consistently ranked 5 by two of the experts while two others ranked it 6 and 9 respectively, highlighting the low significance of crocodiles in comparison to the other resources.

The ESR map in Figure 3 highlights the locations of the most significant and least significant resources to be saved when coordinating an emergency response. The least significant resources are generally concentrated in the southern part of the map (green) while the more significant resources, coded red and orange, are mainly concentrated in the Northern offshore part of Sarawak, bordering Sabah. Based on this color coded delineation, response teams can promptly deploy resources to the high priority areas and attempt to salvage the less priory areas thereafter. Figure 4 reflects the emergency response priorities of expert 2. Mangroves, which are located in the southern offshore region of the study area have a medium priority, in contrast to their low priority in the first expert's rating. The difference in preference ratings is usually due to the diverse backgrounds, experiences and expertise of the different respondents. Hence aggregate ranking that minimizes the sum of deviations from the individual rankings is necessary (Dopazo et al., 2017). The AIP technique (Balogun et al., 2015) was adopted for the aggregation. Tables 5 and 6 show the aggregated preferences of all the four expert respondents.

\begin{tabular}{|c|c|c|c|c|c|c|}
\hline & Respondent 1 & Respondent Z & Respondent 3 & Respondent 4 & & \\
\hline & Fank $|x|$ & Eank (x) & $\operatorname{Rank}(x)$ & $\operatorname{Aanh}(6)$ & Total (x) & Averase(N) \\
\hline Fish & 10.71 & 26.90 & \begin{tabular}{|r|}
16.09 \\
\end{tabular} & 11.65 & 65.34 & 16.34 \\
\hline Turtle & 28.27 & 2.97 & 8.25 & 15.83 & 55.33 & 13.83 \\
\hline Coral & 25.41 & 2.44 & 11.26 & 25.40 & 65.51 & 16.38 \\
\hline Crab & 10.35 & 17,12 & 19,42 & 7,26 & 54.15 & 13.54 \\
\hline Crocodile & 8.02 & 2.98 & 1.78 & 6.46 & 19.25 & 4.81 \\
\hline Dophlins: & 9.03 & 2.04 & 5.34 & 5.29 & 21.70 & 5.42 \\
\hline Mangrove & 3.14 & 9.11 & 4.11 & 21.00 & 37,36 & 9.34 \\
\hline Prawns & 1.81 & 18.20 & 30.35 & 4.11 & 54.47 & 13.62 \\
\hline Shotebitd & 3.26 & 18.25 & 3.39 & 1.99 & 26.89 & 6.72 \\
\hline
\end{tabular}

Table 5: Aggregation of priority weights of all experts

\begin{tabular}{|r|l|r|}
\hline Average(\%) & Type & Rank \\
\hline 16.38 & Coral & 1 \\
\hline 16.34 & Fish & 2 \\
\hline 13.83 & Turtle & 3 \\
\hline 13.62 & Prawns & 4 \\
\hline 13.54 & Crab & 5 \\
\hline 9.34 & Mangrove & 6 \\
\hline 6.72 & Shorebird & 7 \\
\hline 5.42 & Dophlins & 8 \\
\hline 4.81 & Crocodile & 9 \\
\hline
\end{tabular}

Table 6: Aggregated preference rankings of all resources 


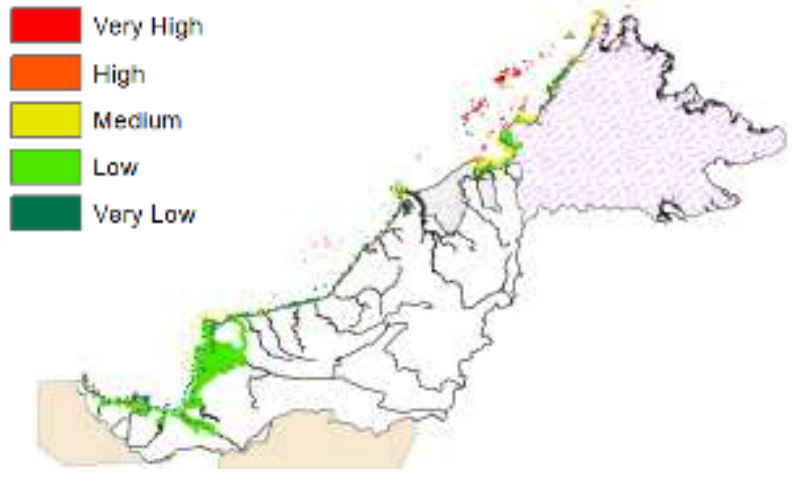

Figure 7: ESR map based on aggregation of expert's prioritization of vulnerable marine resources

The aggregated ranking in Table 6 and corresponding ESR map in Figure 7 show high priority for Coral, Fish, Turtle, Prawns and Crab. Their weight differences are also small, reflecting the overall importance attached to these 5 resources by all respondents collectively. The 5 highly prioritized resources are mainly located in the northernmost part of the offshore area while the least prioritized resources are located in the southernmost part of the offshore area as shown in Figure 7. Deploying these maps and preference weights will facilitate consensus among all stakeholders during emergency situations, and encourage the focused utilization of resources on priority areas. This paper's SDSS has successfully facilitated trade-offs in the various respondent's priority preferences and enabled a consensus via the aggregation of their respective individual preferences. The consensus ESP map (Figure 7) serves as a common operational map capable of providing consistent situational awareness for the multiple parties involved in the disaster response.

Cooperation of multiple stakeholders is crucial to the success of any response strategy for offshore disasters but bringing diverse stakeholders with varied perspectives and backgrounds to agree on the rescue priorities of several environmental resources in the face of limited time, facilities and manpower during rescue operations could be challenging due to the different interests of all parties. This paper's SDSS ESR response system provides a platform for assembling the diverse views of multiple stakeholders and facilitating consensus among them, thereby ensuring prompt and timely intervention and cooperation in optimizing limited rescue resources to minimize damages to the most valuable marine resources.

\section{REFERENCES}

Ansa, E. J., and Akinrotimi, O. A., 2018. Reactions to Petroleum Exploration from Oil-Bearing Communities: What Have We Learned? In: The Political Ecology of Oil and Gas Activities in the Nigerian Aquatic Ecosystem.

Balogun, A.L., 2014. Optimal Offshore Pipeline Corridor and Route Selection using Spatial Decision Support System (SDSS). UTP, Malaysia. PhD Dissertation.

Balogun, A.L., Matori, A.N., and Hamid-Mosaku, A.I., 2015. A fuzzy multi-criteria decision support system for evaluating subsea oil pipeline routing criteria in East Malaysia. Environ Earth Sci. DOI 10.1007/s12665-015-4499-z.

Balogun, A.L., Matori, A.N., and Hamid-Mosaku, A.I., UmarLawal, D., Chandio, I.A., 2016. Fuzzy MCDM-based GIS model for subsea oil pipeline route optimization: An integrated approach. Marine Georesources \& Geotechnology, 35 (7). DOI: 10.1080/1064119X.2016.1269247.

Brimicombe, A., 2010. GIS, Environmental Modeling and Engineering. CRC Press, Taylor \& Francis Group, London.

Chakhar, S. and Martel, J.M., 2003. Enhancing Geographical Information Systems Capabilities with Multi-Criteria Evaluation Functions. Journal of Geographic Information and Decision Analysis 2003, 7(2), pp. 47 - 71

Chiau, W. Y., 2005. Changes in the marine pollution management system in response to the Amorgos oil spill in Taiwan. Mar Pollut Bull, 51(8-12), 1041-1047. doi:10.1016/j.marpolbul.2005.02.048

Chemsain., 2014. 4 EIA Requirement- E-KAS. Executive Summary.

Dopazo, E. and Martínez-Céspedes, M.L., 2017. Rank aggregation methods dealing with ordinal uncertain preferences. Expert Systems with Applications, 78, pp. 103-109

Eastman, J.R., Jin, W., Kyem, P.A.K. and Toledano, J., 1995. Raster procedures for multicriteria/multi-objective decisions. Photogrammetric Engineering and Remote Sensing, 61, pp. 539-547.

Fingas, M., 2012. The basics of oil spill cleanup: CRC Press

Hegde, N., 2001. El Paso proceeding with offshore gas line from Nova Scotia to US. Oil and Gas Journal.

Lynch, L.E., 2015. Statement by Attorney General Loretta E. Lynch on the Agreement in Principle with BP to Settle Civil Claims for the Deepwater Horizon Oil Spill.

Moussaoui, F., Cherrared, M., Kacimi, M.A., and Belarbi, R., 2017. A genetic algorithm to optimize consistency ratio in AHP method for energy performance assessment of residential buildings-Application of top-down and bottom-up approaches in Algerian case study. Sustainable Cities and Society. 
Nord Stream., 2012. A Long-Term Solution for Europe's Energy Security. Nord Stream, Background Information.

Nord Stream., 2008. The new gas supply route to Europe. Nord Stream, FACTS Issue 0/2008.

National Oceanic and Atmospheric Administration., 2017. How oil harms Animals and Plants in Marine Environment.

Singkran, N., 2013. Classifying risk zones by the impacts of oil spills in the coastal waters of Thailand. Marine Pollution Bulletin, 70(1), 34-43.

doi: http://dx.doi.org/10.1016/j.marpolbul.2013.02.004

Smith, C. E., 2012. Near-term pipeline plans grow, longer-term projects sag. Oil \& Gas Journal, 110, pp. 98-100,102,104-111.

Saaty, T. L., and Özdemir, M.S., 2015. How many judges should there be in a group? Annals of Data Science 1:359-68. doi:10.1007/s40745-014-0026-4

Saaty, T.L., 1990. How to Make a Decision: The Analytic Hierarchy Process. European Journal of Operational Research. 48 (1), pp. 9-26.

Zenobi, D., Cimbali, W., Rott, W., and Gjedrem, T., 2012. The Nord Stream Project. Proceedings of the Twenty-second International Offshore and Polar Engineering Conference, Greece. ISOPE. 